\title{
The Effect of Annealing on the Microstructure and Properties of Ultralow-Temperature Rolled Mg-2Y-0.6Nd-0.6Zr Alloy
}

\author{
Hongmin $\mathrm{Yu}^{1,2,3}$, Wei Li ${ }^{1,2,3, * \mathbb{D}}$, Yun Tan ${ }^{1,2,3}$ and Yuanbiao Tan $1,2,3$ \\ 1 College of Material and Metallurgy, Guizhou University, Guiyang 550025, China; \\ yhm19961220@163.com (H.Y.); tyl19941020@163.com (Y.T.); 18892343595@163.com (Y.T.) \\ 2 Guizhou Key Laboratory for Mechanical Behavior and Microstructure of Materials, Guizhou University, \\ Guiyang 550025, China \\ 3 National and Local Joint Engineering Laboratory for High-Performance Metal Structure Material and \\ Advanced Manufacturing Technology, Guiyang 550025, China \\ * Correspondence: wli1@gzu.edu.cn; Tel.: +86-0851-8362-7068
}

check for updates

Citation: Yu, H.; Li, W.; Tan, Y.; Tan, Y. The Effect of Annealing on the Microstructure and Properties of Ultralow-Temperature Rolled Mg-2Y-0.6Nd-0.6Zr Alloy. Metals 2021, 11, 315. https://doi.org/ $10.3390 /$ met11020315

Academic Editor: Hamid Jahed

Received: 26 January 2021

Accepted: 8 February 2021

Published: 11 February 2021

Publisher's Note: MDPI stays neutral with regard to jurisdictional claims in published maps and institutional affiliations.

Copyright: (c) 2021 by the authors. Licensee MDPI, Basel, Switzerland. This article is an open access article distributed under the terms and conditions of the Creative Commons Attribution (CC BY) license (https:/ / creativecommons.org/licenses/by/ $4.0 /)$.

\begin{abstract}
Mg}-2 \mathrm{Y}-0.6 \mathrm{Nd}-0.6 \mathrm{Zr}$ alloy was first deformed by equal channel angular pressing (ECAP), then rolled and deformed under ultralow temperature conditions (liquid nitrogen immersion), and finally annealed. Optical microscopy (OM), electron backscatter diffraction technology (EBSD), and transmission electron microscopy (TEM) were used to analyze the evolution of the multiscale microstructure and changes in the mechanical properties of the alloy under ultralow temperatures and various annealing conditions. The results showed that the alloy treated with ECAP obtained fine grains, and a large number of fine twins were formed during the ultralow-temperature rolling process, which promoted the improvement of its hardness and strength and provided numerous preferential nucleation sites. The annealing made it easier to induce recrystallization and improve the recrystallization nucleation rate. The twin boundary produced by the alloy after ultralow-temperature rolling and the uniform fine grains formed by annealing resulted in excellent strength and plasticity of the alloy. The twins formed after rolling under ultralow temperatures were mainly $\{1012\}<1011>$ tensile twins. The alloy had comprehensive mechanical properties with a tensile strength of 186.15 $\mathrm{MPa}$ and an elongation of $29 \%$ after annealing at $350{ }^{\circ} \mathrm{C}$ for $10 \mathrm{~min}$.
\end{abstract}

Keywords: magnesium alloy; ultralow-temperature rolled; annealing; recrystallization; twin

\section{Introduction}

Magnesium alloys offer the advantages of low density, high specific strength, high specific rigidity, excellent electromagnetic shielding effectiveness, and recyclability. These materials have broad prospects for industrial applications, such as in aerospace and electronics, and are known as the "green structural engineering materials of the 21st century" [1]. Magnesium and magnesium alloys have a hexagonal close-packed (HCP) crystal structure; thus, under low-temperature deformation, it is difficult to activate slip, facilitating the formation of a strong texture and resulting in poor room-temperature formability, which limits the wide application of magnesium alloys in engineering materials [2-5]. With the development of modern industrial technology, more and more structural parts require materials that have both high strength and good plasticity. In recent decades, many severe plastic deformation (SPD) technologies for obtaining ultrafine grain (UFG) materials have been developed, including high-pressure torsion (HPT) [6,7], multiaxial forging (MAF) [8,9], accumulative roll-bonding (ARB) [10,11], and equal channel angular pressing (ECAP) [12-14]. These deformation methods can obtain ultrafine grains, but the plasticity and thermal stability of the structure obtained by these deformation methods are poor. Jahadi et al. [15] studied the effect of ECAP process on the microstructure and mechanical properties of forged AM30 magnesium alloy. They found that the alloy grain size was refined after four passes ECAP at $275^{\circ} \mathrm{C}$, and the mechanical properties were 
improved. Garces et al. [16] also found that ECAP can achieve the effect of fine grain strengthening.

Researching how to obtain high-strength materials with good plasticity and thermal stability has important theoretical significance and application value. Sarker et al. [17] studied the change of twin width caused by detwinning and the subsequent change of texture composition strength by changing the loading direction of predeformed AM30 magnesium alloy and found that the twin width decreased linearly with the increase of true strain. Sarker et al. [18] studied the change of twin width in extruded magnesium alloy during compression and found that the twin had three growth stages with the increase of strain due to the interaction between twin and dislocation. Sarker et al. [19] studied the plastic deformation of AM30 magnesium alloy in extrusion direction, which could be divided into three different stages. With the decrease of strain hardening rate, twinning occurred in stage A. In stage B, there was a strong twin dislocation interaction, which showed that the strain hardening rate increased with the extension of strain range. In stage $\mathrm{C}$, the strain hardening rate decreased due to the decrease of twin resistance to dislocation slip. Sarker et al. [20] studied the effect of twinning induced by prestrain on the subsequent texture and hardening behavior of extruded AM30 alloy. It was observed that in two-step extrusion direction (ED) and transverse direction (TD) compression, with the increase of prestrain, the YS strength and bending strength increased and the hardening ability decreased. In the second compression process, new twins were formed along the TD direction, which led to grain refinement, thus increasing the yield strength (YS) effect based on the Hall-Petch relationship. Sarker et al. [21] explored the relationship between hardening behavior, texture evolution, and detwinning of extruded AM30 alloy when the strain path was changed. It was found that detwinning occurred with the increase of prestrain, and the texture was weakened by precompression in the ED and recompression in the normal direction (ND). Sarker et al. [22] studied the texture composition of AM30 magnesium alloy and its evolution with increasing compression strain and found that the $c$-axis always rotated in the direction of anticompression due to the tensile twins. Although twins can be obtained by compression at room temperature, a large number of twin boundaries will be obtained by reducing the rolling temperature, and better strength and hardness will be obtained. A large number of twin boundaries can be obtained through ultralow-temperature deformation, which can be equivalent to grain boundaries, strengthening metal materials by effectively hindering the movement of dislocations [23].

After ultralow-temperature rolling, the strength of the alloy is greatly improved, but its plasticity is greatly reduced. To make an alloy with high strength and good plasticity is therefore a challenge. The room temperature formability of the alloy can be further improved by refining the grain structure and improving the texture [24-26]. Two methods are generally used for magnesium alloy matrixes; one method is to control the activity of deformation twins and to promote the activation of nonbasal surface slip, and the second method is to refine the grain structure and improve the texture by cold deformation and subsequent annealing to form static recrystallization. Ultralow-temperature rolling is more conducive to twinning deformation of metals by reducing the deformation temperature because the dislocation movement requires greater stress at lower temperatures, making it difficult for the dislocation to slip and climb. Therefore, it can accumulate a large amount of high-energy positions to provide more preferential nucleation positions for subsequent annealing, which is more conducive to the formation of finer and uniform recrystallized grains during the annealing process, meaning the alloy has excellent plasticity. Sarker et al. [27] studied the recrystallization behavior of precompressed AM30 magnesium alloy and the microstructure and texture changes of annealed samples during compression. It was found that the twins in precompressed AM30 magnesium alloy gradually disappeared, the volume fraction of twins decreased, and the texture weakened with the increase of annealing time, while the compress yield strength (CYS) decreased and the fracture strain increased with the increase of annealing temperature. Kim et al. [28] studied the changes in twinning and annealing behavior caused by the difference in grain size within the material 
and found that the microstructure difference between the coarse-grained region and the fine-grained region caused by the precompression in the subsequent annealing process almost disappeared and got a uniform microstructure. Song et al. [29] used a process route combining equal channel angular extrusion and annealing to simultaneously improve the corrosion resistance and mechanical properties of $\mathrm{Mg}-2 \mathrm{Zn}-\mathrm{Mn}-\mathrm{Ca}-\mathrm{Ce}$ alloy and achieved double yield/ultimate strength and elongation, while the mechanical integrity of the alloy was better maintained after corrosion. Chen et al. [30] used cumulative cold rolling and intermediate annealing processes to prepare ultrafine-grained ZK61 magnesium alloy sheets. Multiple static recrystallizations clearly achieved refinement and homogenization of the structure during this process. Guo et al. [31] studied the effects of recrystallization and grain growth during annealing in optimizing the texture of calcium-added magnesium alloy sheets and found that the recrystallized nucleus retained the orientation of its deformed matrix in AZ31, which provided limited potential for optimizing texture through annealing treatment. Therefore, it can be seen that the alloy can obtain good plasticity during the annealing process.

The purpose of this work was to study the static recrystallization behavior of the subsequent annealed alloy as well as the change rule of twinning in the process of static recrystallization and its influence on the microstructure and mechanical properties by improving the traditional deformation process and introducing a large number of dislocations and twins after grain refinement.

\section{Material and Methods}

The experimental material was as-cast $\mathrm{Mg}-2 \mathrm{Y}-0.6 \mathrm{Nd}-0.6 \mathrm{Zr}$ alloy. The central portion of an ingot of the material was cut, and it was processed into $\Phi 12 \mathrm{~mm} \times 80 \mathrm{~mm}$, followed by homogenization at $450^{\circ} \mathrm{C}$ for $6 \mathrm{~h}$.

The ECAP die structure used in the experiment is shown in Figure 1, where $\varphi=120^{\circ}$, $\Psi=30^{\circ}$, the extrusion path is the $\mathrm{Bc}$ (that is, rotated $90^{\circ}$ around the longitudinal axis of the sample in a counter-clockwise direction after each extrusion pass), ND and ED (RD) represent the normal and extrusion direction (rolling direction) in the sample, and TD is the transverse direction. A total of four ECAP extrusion passes were made. The deformation temperature was $400{ }^{\circ} \mathrm{C}$ for the first two passes and $350{ }^{\circ} \mathrm{C}$ for the last two passes; the sample was kept warm for $10 \mathrm{~min}$ before each pass at an extrusion speed of $0.4 \mathrm{~mm} / \mathrm{s}$. A three-phase asynchronous rolling mill was used to carry out rolling tests on the extruded alloy at a speed of $970 \mathrm{r} \cdot \mathrm{min}^{-1}$ under ultralow temperature conditions for two rolling passes. The bar was soaked in liquid nitrogen for approximately $15 \mathrm{~min}$ before each rolling pass, and the sample was rotated $90^{\circ}$ along the axis before the second rolling. After the rolling was completed, the sample was soaked in liquid nitrogen for approximately $10 \mathrm{~min}$ before removal from the mill. Finally, the samples were annealed under different conditions at annealing temperatures of 250,300 , and $350{ }^{\circ} \mathrm{C}$ with a $1 \mathrm{~h}$ holding time; the optimal high temperature was selected as $350^{\circ} \mathrm{C}$. A short annealing time was used to observe and analyze the effect of changes in the twins and the dislocation content on the properties of magnesium alloys, that is, annealing times of 3, 6, 10, and 30 min were investigated, with air cooling after annealing.

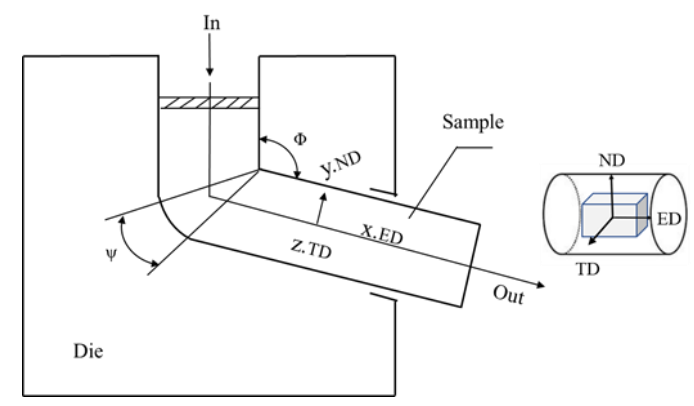

Figure 1. Equal channel angular pressing (ECAP) mold structure. 
All the observation surfaces used for testing are $\operatorname{ED}(\mathrm{RD})$ - ND. For simplicity, the ultralow-temperature rolled $\mathrm{Mg}-2 \mathrm{Y}-0.6 \mathrm{Nd}-0.6 \mathrm{Zr}$ alloy (ECAP + rolling) is referred to as the ultralow-temperature rolled alloy. The sample was ground with $400 \# \sim 10000$ \# sandpaper, then polished to a "mirror surface" effect, and lastly corroded with picric acid etching solution. The microstructure of the ultralow-temperature rolled samples was observed before and after annealing with an OLMPUS-BH2 optical microscope (Olympus, Tokyo, Japan). Image-Pro Plus image analysis software (Image-Pro Plus 6.0, Media Cybernetics, Inc., Rockville, MD, USA) was used to measure the grain size by the average linear intercept method. The samples were tested with a HV-1000 digital microhardness tester (Suzhou Haichuan Science and Education Equipment Co. Ltd, Suzhou, China) under a $100 \mathrm{~g}$ load with a loading time of $15 \mathrm{~s}$ and a holding time of $10 \mathrm{~s}$. Because the uneven deformation at both ends of the sample needed to be removed, it could not reach the standard size length. Therefore, the nonstandard size with extensometer was adopted. Figure 2 shows that the tensile sample adopted a sheet-like nonstandard size because of sample size limitations. An Instron 5565 electronic universal testing machine (Instrang Shanghai Test Equipment Trading Co., Ltd. Instron, Shanghai, China) was used to measure the tensile properties of the sample. At least three samples for each state were tested at a tensile rate of $0.51 \mathrm{~mm} / \mathrm{min}$. The microtexture and grain orientation of the overall alloy structure were tested by electron backscatter diffraction technology (EBSD) with a S-3400 N scanning electron microscope (German Zeiss, Jena, German). Thin-slice samples with $5 \mathrm{~mm}$ length, $5 \mathrm{~mm}$ width, and $1 \mathrm{~mm}$ thickness were cut from the middle of the sample. Firstly, the samples were mechanically polished with 400 \# 3000 \#-SiC water-abrasive paper. Then, the observation surface of the sample was mechanically polished with alumina slurry to obtain the ideal state of bright surface and no scratch. Leica EMRES 102 argon ion polishing instrument (Leica Microsystems Shanghai Trading Co., Ltd., Shanghai, China) was used to polish the EBSD samples, and the specimens were polished according to the following sequence of polishing parameters: (1) voltage of $5 \mathrm{KV}$, ion gun angle of $15^{\circ}$, and polishing time of $40 \mathrm{~min}$; (2) voltage of $4.5 \mathrm{KV}$, ion gun angle of $15^{\circ}$, and polishing time of $50 \mathrm{~min}$; (3) voltage of $3.5 \mathrm{KV}$, ion gun angle unchanged, and low-voltage polishing time of $60 \mathrm{~min}$. The sample was inclined at $70^{\circ}$, the acceleration voltage was $20 \mathrm{KV}$, the beam density was $18 \mathrm{~A} / \mathrm{m}^{2}$, the step size EBSD scan was $0.6 \mu \mathrm{m}$, and the working distance was 15-16 mm. Channel 5 software (Oxford Instruments, Abingdon, UK) was used for statistics and analysis of EBSD data. To prepare transmission electron microscopy (TEM) sample, the sample was first cut into a disc with a thickness of $1 \mathrm{~mm}$ and then mechanically ground to a thickness of less than $50 \mathrm{~mm}$. Then, a sample with a diameter of $3 \mathrm{~mm}$ was punched out from the cutting disc. The thin area was obtained by ion milling, and Gatan 691 argon ion polishing instrument (Gatan Inc., Pleasanton, CA, USA) was used to polish the TEM samples. The specimens were polished according to the following sequence of polishing parameters: (1) thinning: voltage of $5.3 \mathrm{KV}$, ion gun angle of $8^{\circ}$, and polishing time of $50 \mathrm{~min}$; (2) expansion: voltage of $4.5 \mathrm{KV}$, ion gun angle of $5^{\circ}$, and polishing time of $30 \mathrm{~min}$; (3) thinning: voltage of $3.6 \mathrm{KV}$, ion gun angle of $3^{\circ}$, and low-voltage polishing time of $15 \mathrm{~min}$. The dislocations and twins were observed and analyzed by a FEI Talos F200X TEM (FEI Company, Hillsboro, OR, USA).

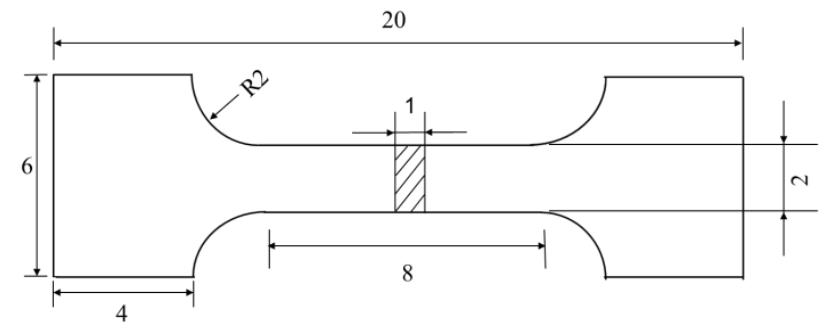

Figure 2. Dimension diagram of tensile specimen (units: $\mathrm{mm}$ ). 


\section{Results and Discussion}

\subsection{Microstructure Analysis}

Figure 3 shows the microstructure of an ultralow-temperature rolled alloy annealed at different temperatures for $1 \mathrm{~h}$. As shown in Figure 3a, the large degree of deformation of the alloy produced a large number of twins and elongated deformed grains in the structure. Figure $3 \mathrm{~b}$ demonstrates that after annealing the alloy at $250{ }^{\circ} \mathrm{C}$ for $1 \mathrm{~h}$, there were more twins and deformed grains within the structure as well as more fine recrystallized grains, which were mainly distributed in the crystal grains. The distortion energy was higher in some regions of the grains, such as the boundary and the twin junction. After annealing the alloy at $300^{\circ} \mathrm{C}$ for $1 \mathrm{~h}$, gradual growth of the recrystallized grains resulted in few twins, as shown in Figure 3c. Increasing the temperature to $350{ }^{\circ} \mathrm{C}$ caused the twin to disappear, and more uniform equiaxed grains were formed.
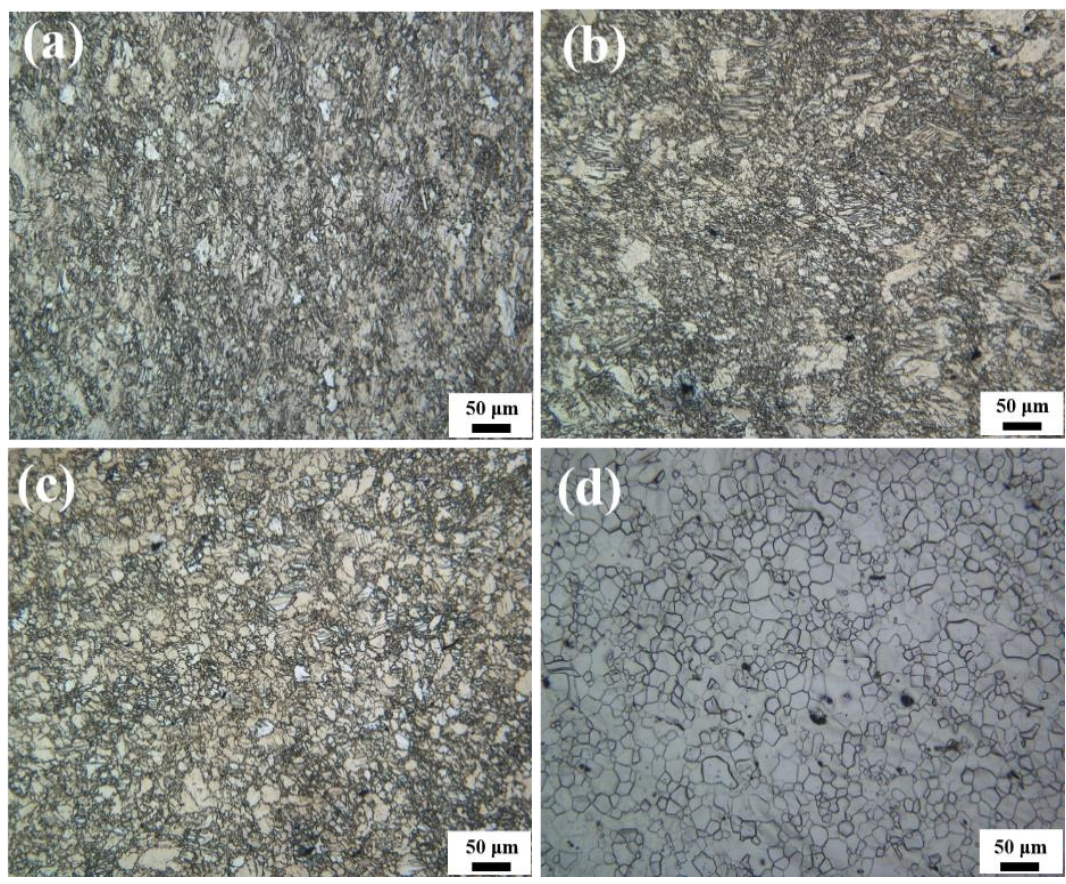

Figure 3. Microstructure of ultralow-temperature rolled alloy (a) before annealing and (b-d) after annealing at various temperatures: (b) $250^{\circ} \mathrm{C}$, (c) $300{ }^{\circ} \mathrm{C}$, and (d) $350{ }^{\circ} \mathrm{C}$.

Recrystallized grains first nucleate and grow in the high-energy regions of a grain and then expand to spread over the entire grain. High-energy regions, such as highdensity dislocation areas, junction of twin boundaries, and grain boundaries, provide preferential recrystallization sites during heat treatment. The deformation twins formed by ultralow-temperature rolling can increase the grain boundary energy inside grains and effectively prevent the excessive growth of recrystallized grains. Figure 4 indicates that the microstructure was gradually transformed from deformed grains formed by ultralowtemperature rolling to undistorted equiaxed grains of annealing for different times at $350{ }^{\circ} \mathrm{C}$. It is noticeable from Figure $4 \mathrm{~b}$ that after annealing the sample at $350{ }^{\circ} \mathrm{C}$ for $3 \mathrm{~min}$, many twins remained in the sample interior and many fine static recrystallized grains appeared in the unevenly deformed structure, mainly in the interior of metastable grains and grain boundaries. As shown in Figure 4c, a few twins remained in the structure, and the grains had not yet completed the static recrystallization process after annealing the sample for $6 \mathrm{~min}$. This result was obtained because the short annealing period did not provide sufficient time and energy for small grains to nucleate and grow. As can be seen from Figure $4 d$, the deformed grains gradually became fine recrystallized grains after annealing the sample for $10 \mathrm{~min}$. As shown in Figure 4e, the entire metallographic structure was composed of uniformly sized equiaxed grains after annealing the alloy for $30 \mathrm{~min}$. The 
static recrystallization process was completed, and the resulting grains were approximately $15.5 \mu \mathrm{m}$ in size on average.

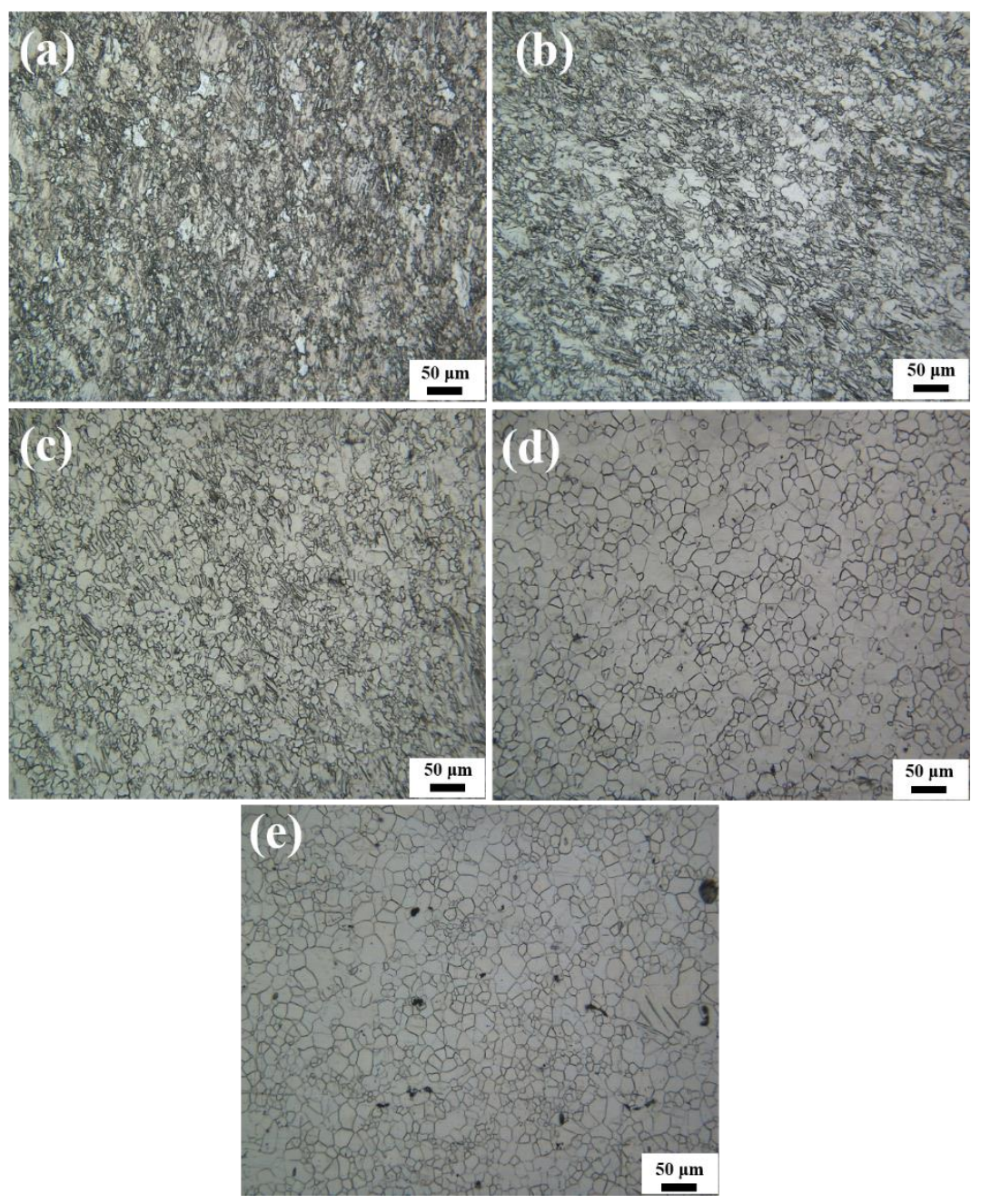

Figure 4. Microstructure of ultralow-temperature rolled alloy (a) before annealing and (b-e) after annealing for different times: (b) $3 \mathrm{~min},(\mathbf{c}) 6 \mathrm{~min},(\mathbf{d}) 10 \mathrm{~min}$ and (e) $30 \mathrm{~min}$.

\subsection{TEM Analysis}

In order to observe the dislocation changes and the formation of recrystallized grains of the alloy before and after annealing, the bright field image of the sample before and after annealing at $350{ }^{\circ} \mathrm{C}$ for $10 \mathrm{~min}$ (Figure 5) was used for observation and analysis. It can be seen from Figure $5 \mathrm{a}, \mathrm{c}$ that a large accumulated strain resulted in a high density of dislocation after the alloys underwent ultralow-temperature rolling. It is interesting to note that these high-density dislocations entangled and accumulated near the grain boundaries into dislocation cells, and the grain boundaries were rough. It can be seen from Figure $5 \mathrm{~b}, \mathrm{~d}$ that for the sample annealed at $350{ }^{\circ} \mathrm{C}$ for $10 \mathrm{~min}$, part of the dislocation cell shape occurred during the annealing process, and the cell walls were flattened to form subgarins. The original rough grain boundaries also became smooth. In addition, the subgrain boundaries with larger dislocation density migrated toward the surrounding subgrains with larger dislocation difference and swallowed adjacent deformations. The deformed grains and subgrains were gradually transformed into high-angle grain boundaries, becoming the center of recrystallization nucleation and growing to form recrystallized grains. The original dislocation entanglement position distribution became dispersed, and the grain boundaries were clear between recrystallized grains. 

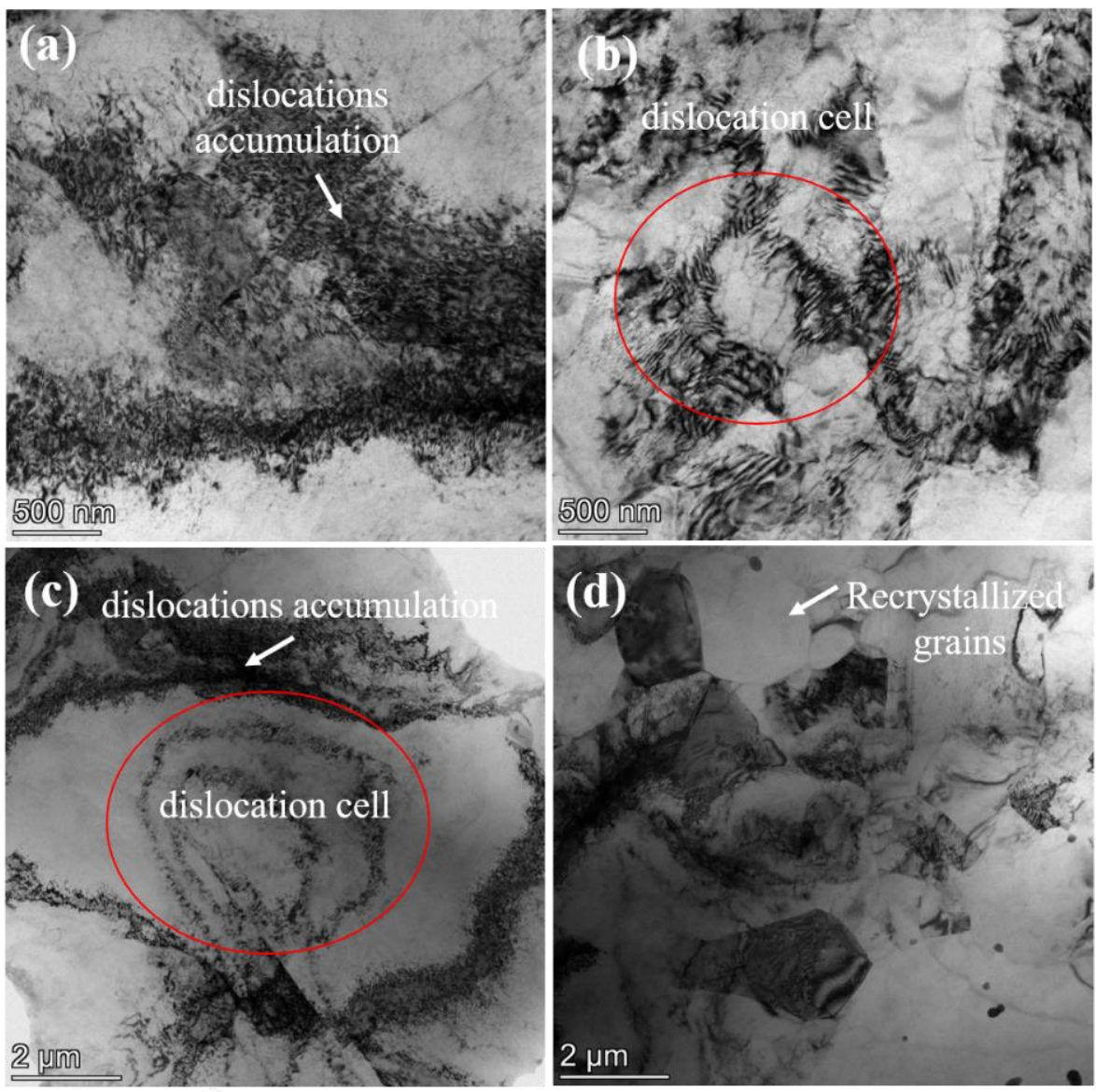

Figure 5. Bright field images of ultralow-temperature rolled sample before and after annealing at $350{ }^{\circ} \mathrm{C}$ for $10 \mathrm{~min}$. (a,c) $0 \mathrm{~min},(\mathbf{b}, \mathbf{d}) 10 \mathrm{~min}$. (Note: there could be the possible formation of an artificial generation of few small dislocations during ion milling.)

Figure 6 shows TEM and the corresponding selected area electron diffraction images of the alloy. As can be seen from Figure 6a, the dislocation density of the alloy was relatively high after ultralow-temperature rolling, and a high-density dislocation zone was formed around the twins with staggered dislocations. It is clear from Figure $6 \mathrm{c}$ that the deformation twin boundary was not straight, and the nearby lattice stripes of the matrix and twins overlapped. The arrow in the figure shows that stacking faults on the basal plane were observed in both the matrix and the twins at the atomic scale, which is similar to the results observed by Matsuda et al. [32] in their study on the interaction between a long-period stacked ordered phase and deformation twins in the rapid solidification of a $\mathrm{Mg}_{97} \mathrm{Zn}_{1} \mathrm{Y}_{2}$ alloy. Diffraction calibration of the twins in the selected area showed that these spots were the diffraction spots of $\{10 \overline{1} 2\}$ tensile twins. This result was obtained because the tension force on the $c$-axis mainly produces $\{10 \overline{1} 2\}<\overline{1} 011>$ tensile twins during alloy deformation. The critical shear stress of 1-2 MPa [33] of $\{10 \overline{1} 2\}$ tensile twins is very small. The external force exerted by the deformation of the alloy under ultralow temperature conditions can easily reach the critical shear stress. 

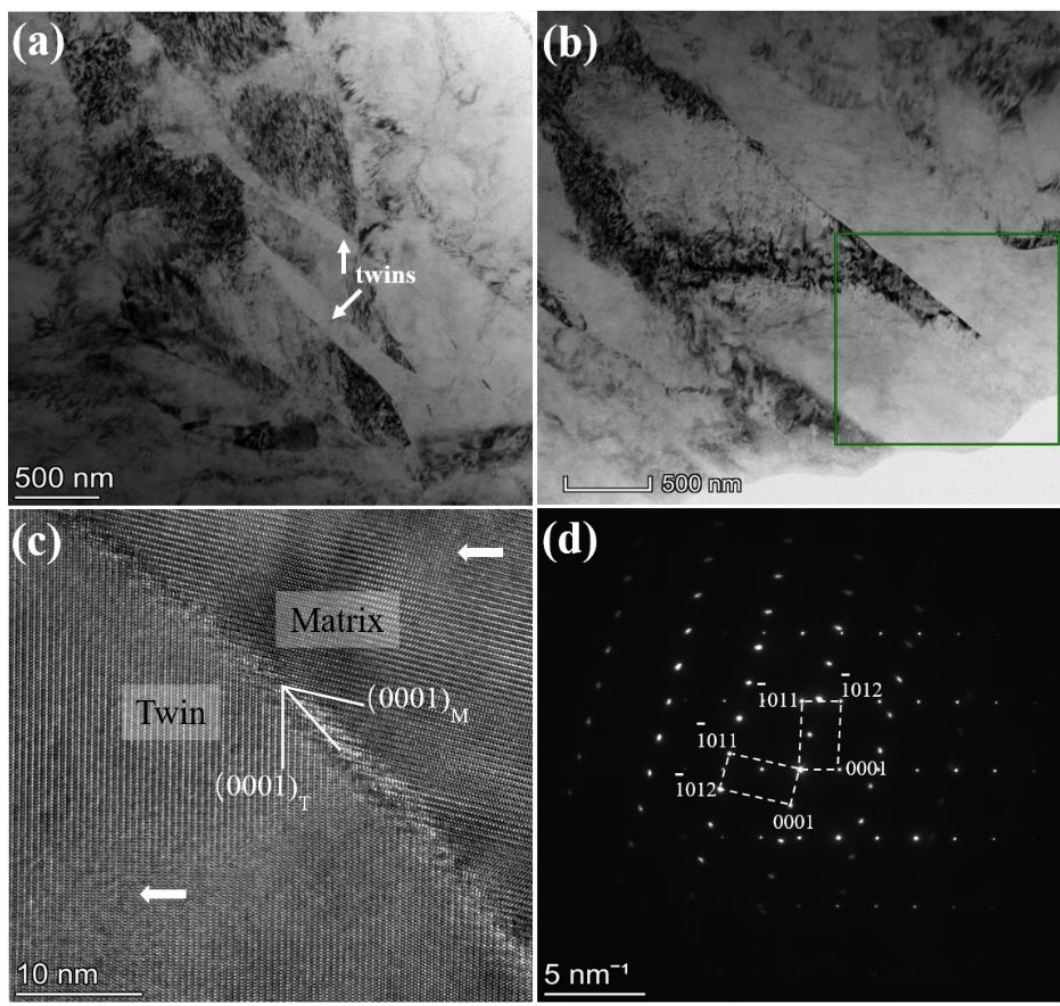

Figure 6. Transmission electron microscopy (TEM) and selected area electron diffraction (SAED) images of ultralow-temperature rolled alloy: $(\mathbf{a}, \mathbf{b})$ bright field images, $(\mathbf{c})$ b-pattern twin and twodimensional lattice diagram near a boundary, and (d) diffraction pattern corresponding to twin crystal area. (Note: there could be the possible formation of an artificial generation of few dislocations during ion milling.)

\subsection{EBSD Analysis}

Ultralow-temperature rolled alloy has a large storage capacity, and its driving force for recrystallization during the annealing process is also large, meaning the degree of recrystallization is high. Figure 7 presents a distribution map of recrystallized grains of the ultralow-temperature rolled alloy at $350^{\circ} \mathrm{C}$ before and after annealing for different times. As the annealing time increased, the proportion of deformed grains (red) decreased sharply, the number of subcrystalline grains (yellow) increased, and the fraction of recrystallized grains (blue) increased from $11.62 \%$ to $39.55 \%$. The occurrence of static recrystallization considerably weakened the strong texture formed during the deformation process and softened the structure. It is apparent from Figure $7 \mathrm{~d}$ that for the ultralow-temperature rolled alloy annealed at $350^{\circ} \mathrm{C}$ for $10 \mathrm{~min}$, a large number of fine grains appeared compared to annealing for 3 and $5 \mathrm{~min}$ (Figure $7 \mathrm{~b}, \mathrm{c}$ ). Because the recrystallization process is controlled by thermal activation, the recrystallization temperature will reduce with the increase of annealing time, the recrystallization nucleation is faster, and the amount of nucleation per unit volume is more, meaning the final recrystallization grain size is smaller.

Figure 8 manifests images of the grain orientation of the alloy before and after annealing at $350{ }^{\circ} \mathrm{C}$ for different times. There are a host of twins and elongated deformed grains in ultralow-temperature rolled alloy, including many metastable structures inside the grains, generous dislocation entanglements, and dislocation cells, which strengthen the basal plane orientation of the alloy grains. The rolled alloy has a relatively large internal strain and stored distortion energy such that the high-energy regions act as nucleation sites during subsequent annealing, resulting in the formation of many fine recrystallized grains. Because the growth of the recrystallized core is realized by migration of the large-angle interface, the recrystallization will eliminate or change the original deformation texture. As the annealing time increased, the deformation texture was greatly reduced, and the 
recrystallization texture was significantly increased. The basal-oriented crystal grains were significantly reduced, and the column-oriented crystal grains increased, that is, the blue crystal grains increased.

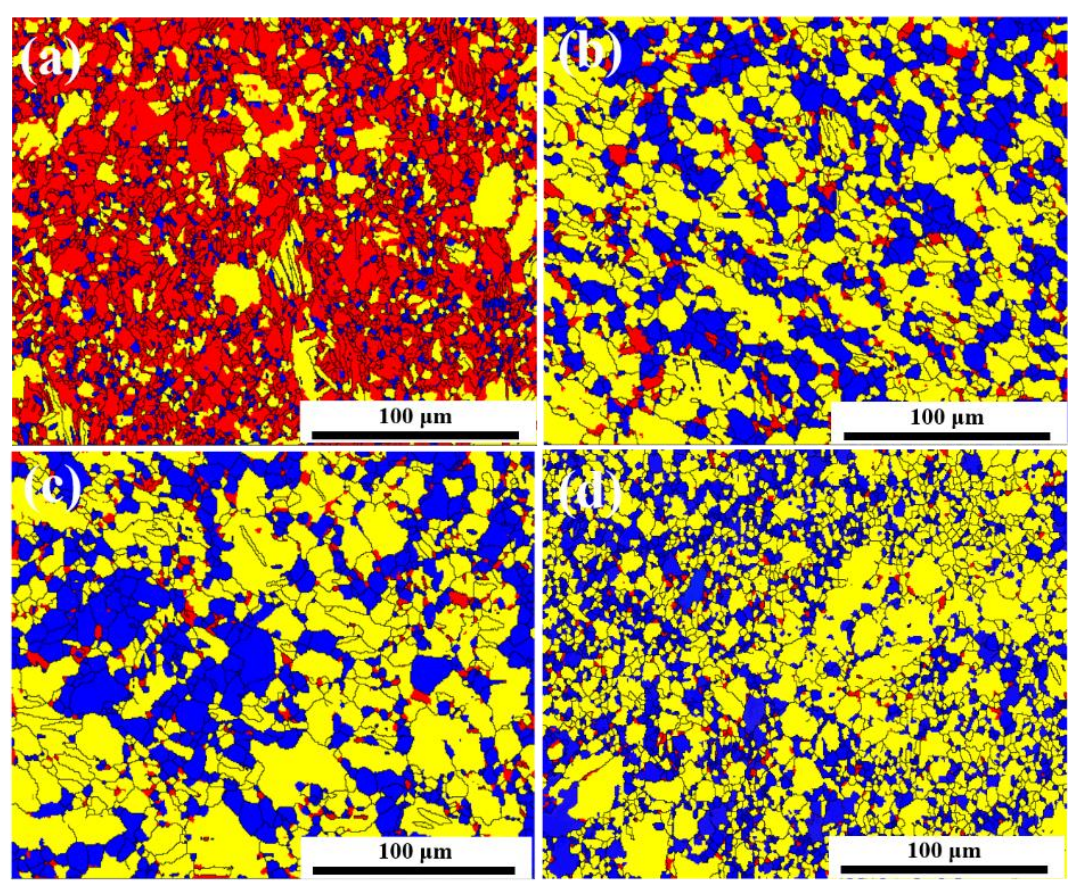

Figure 7. Distribution map of recrystallized grains of ultralow-temperature rolled alloy (a) before annealing and (b-d) after annealing for different times: (b) $3 \mathrm{~min}$, (c) $6 \mathrm{~min}$, and (d) $10 \mathrm{~min}$.

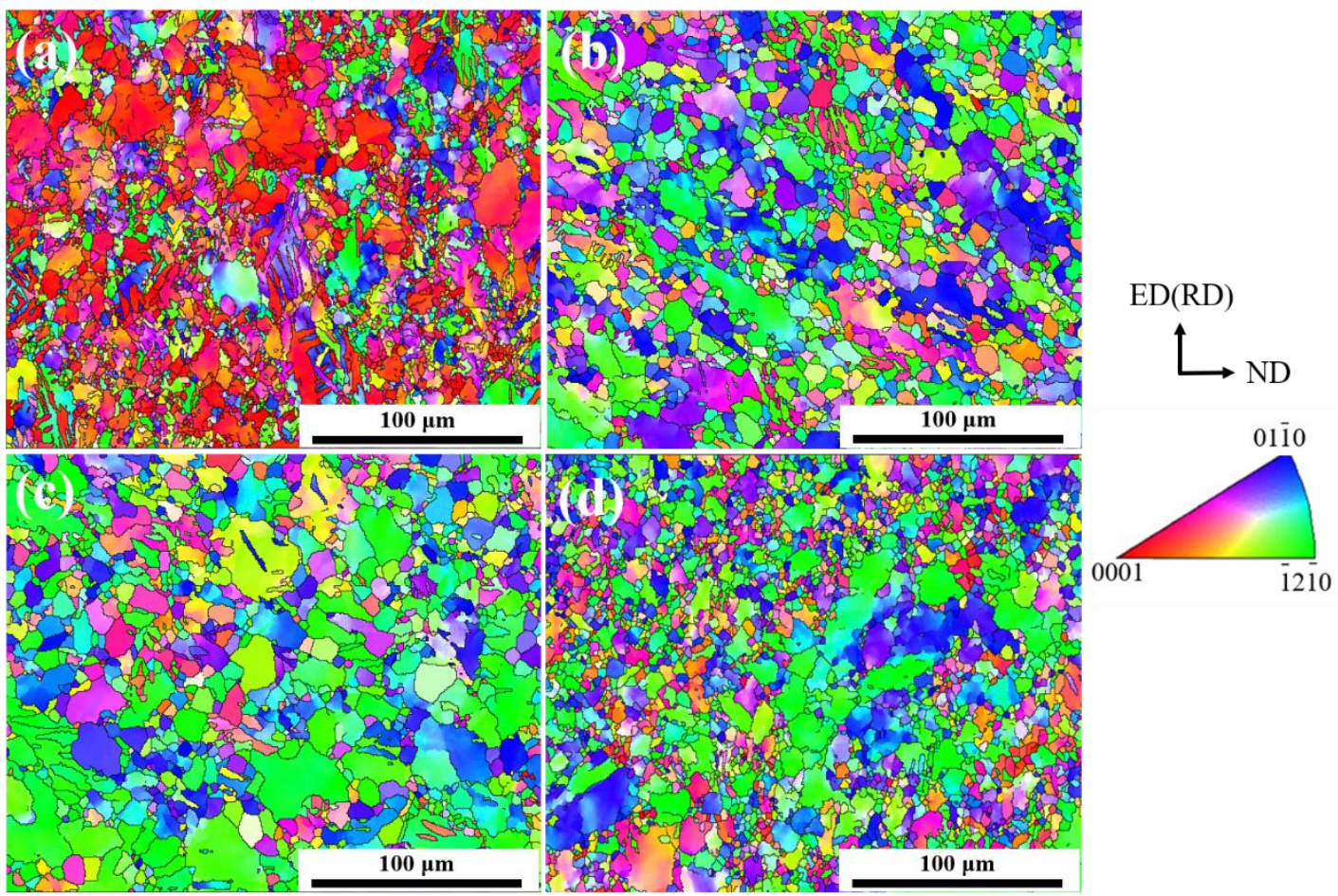

Figure 8. Image showing grain orientation image of ultralow-temperature rolled alloy (a) before annealing and (b-d) after annealing at different times: (b) $3 \mathrm{~min}$, (c) $6 \mathrm{~min}$, and (d) $10 \mathrm{~min}$. 
The phase difference $(\theta)$ between adjacent grains is used to divide the grain boundaries into low-angle grain boundaries (LAGB, $2^{\circ}<\theta<10^{\circ}$ ) and high-angle grain boundaries $\left(\mathrm{HAGB}, \theta>10^{\circ}\right.$ ). Figure 9 is a misorientation distribution diagram of the alloy before and after annealing at $350{ }^{\circ} \mathrm{C}$ for different times, showing the peak distribution of the misorientation angle at approximately less than $10^{\circ}$ and a significant increase in the peak orientation angle at approximately $86^{\circ}$. As shown in Figure $9 \mathrm{a}$, the peak at $86^{\circ}$ was higher than at the other angles, except for dislocation slip and grain boundary sliding, where $\{10 \overline{1} 2\}\left(86^{\circ}<11 \overline{2} 0>\right)$ tensile twinning also contributed to plastic deformation under this condition. This result shows that due to the low critical shear stress, $86^{\circ}$ tensile twins were preferentially generated at the initial stage of plastic deformation. Grain boundaries and twin boundaries hindered the movement of dislocations during plastic deformation, resulting in the accumulation of dislocations; furthermore, the twins generated at the initial stage of plastic deformation changed the grain orientation, thereby activating the nonbasal surface slip system and promoting interactions among the grain boundaries, twin boundaries, and dislocations in the subsequent deformation process, which enhanced the room-temperature tensile plastic deformation ability of the alloy. The ultralow-temperature rolled alloy promoted the formation of a wide range of low-angle grain boundaries due to the interaction of high-density twin boundaries and adjacent dislocations. Statistics of the high-angle and low-angle grain boundaries under different conditions showed that the proportion of low-angle grain boundaries in the ultralow-temperature rolled alloy was $54.9 \%$ after annealing at different times. The proportion of high-angle grain boundaries increased, in contrast to the decrease in the proportion of low-angle grain boundaries. In addition, after annealing at $350{ }^{\circ} \mathrm{C}$ for 3,6 , and $10 \mathrm{~min}$, the proportions of the low-angle grain boundaries were $43.8 \%, 34.8 \%$, and $33.4 \%$ respectively. Combined with Figure $6 a$, it can be seen that a large number of dislocation entanglements and dislocation cells were generated inside the grains of the ultralow-temperature rolled alloy. The walls of the dislocation cells were entangled with a large number of dislocations, forming a low-angle grain boundary by dislocation plugging. The accumulation of the dislocation density resulted in the formation of a dislocation packing area, which increased the internal distortion of the material, and abundant dislocations entangled into a subcrystalline structure. During annealing, subgrains with high dislocation densities migrated to surrounding subgrains with larger orientation differences such that the adjacent deformed matrix was swallowed into subgrain growth; thus, the phase difference between adjacent subgrains increased and gradually transformed into high-angle grain boundaries that served as recrystallization nucleation sites and grew further, increasing the proportion of high-angle grain boundaries. Consequently, the proportion of low-angle grain boundaries decreased, that is, the dislocation density decreased.

The ultralow-temperature rolling of the alloy increased the critical shear stress (CRSS) for basal slip such that the twin deformation became the main deformation mechanism, and the large number of twins produced promoted further plastic deformation of the alloy. Figure 10 shows that the distribution of twin boundaries of the alloy before and after annealing at $350{ }^{\circ} \mathrm{C}$ for different times. The four types of twins shown in four different colors were mainly $86^{\circ}<11 \overline{2} 0>$ tensile twins, a few $56^{\circ}<11 \overline{2} 0>$ compression twins, $64^{\circ}$ $<11 \overline{2} 0>$ compression twins, and $38^{\circ}<11 \overline{2} 0>$ secondary twins. A large number of twins formed during ultralow-temperature deformation were swallowed and consumed during recrystallization; thus, the twin content gradually decreased. Channel 5 software was used to calculate the proportion of twin boundaries and it was found that the ultralowtemperature rolled alloy $86^{\circ}<11 \overline{2} 0>$ tensile twin content was $14.09 \%$, followed by $6.57 \%$, $5.25 \%$, and $1.22 \%$ after annealing. Rolling at an ultralow temperature pulled the alloy material along the $c$-axis direction, making it easy to reach the small required critical shear stress of $\{10 \overline{1} 2\}$ tensile twins; consequently, the magnesium alloys in this study were dominated by $86^{\circ}<11 \overline{2} 0>$ tensile twins during the deformation process. Figure 10 also 
demonstrates that the $86^{\circ}<11 \overline{20}>$ tensile twins accounted for the highest proportion of all twins before and after annealing, and this gradually decreased in number as the annealing time increased.
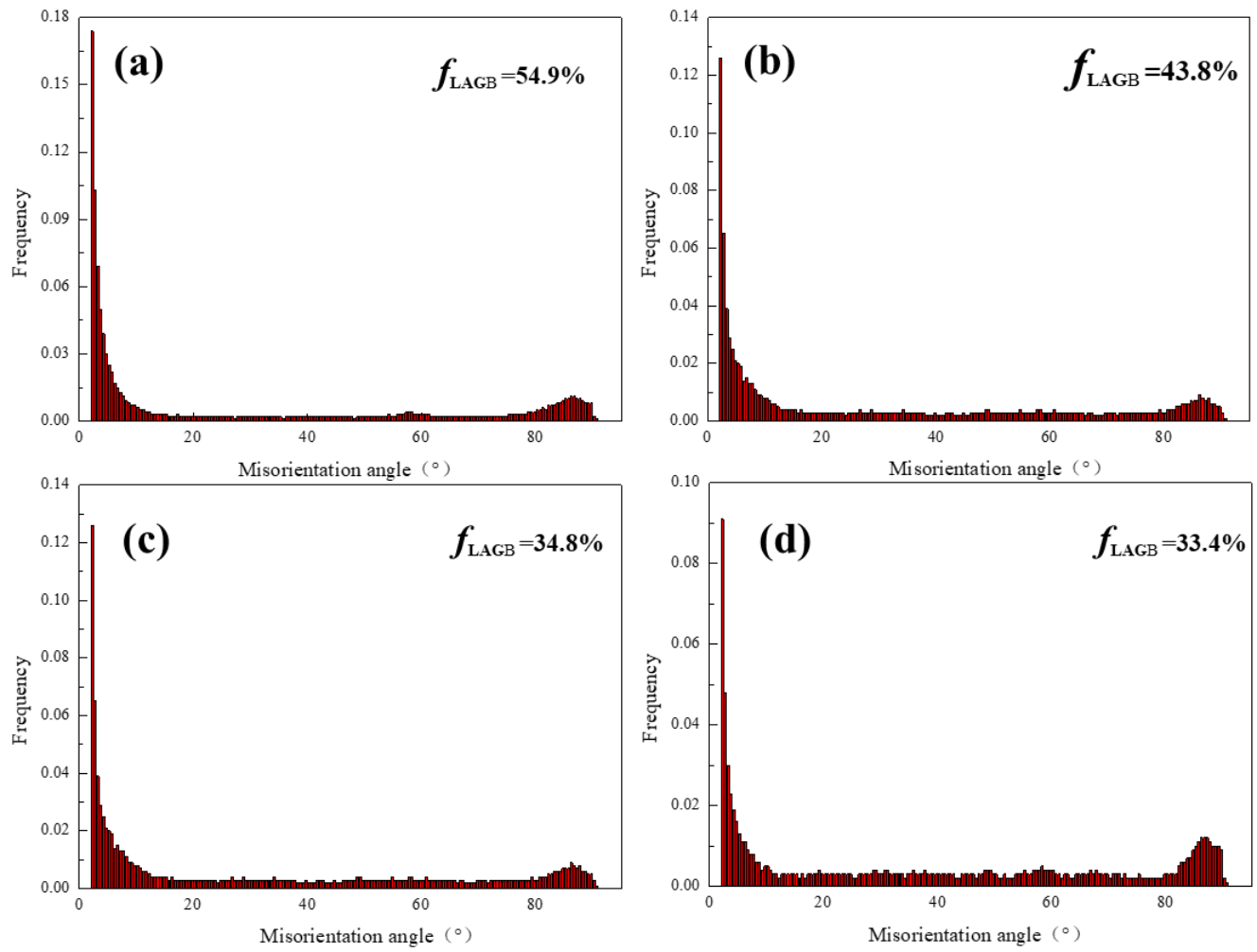

Figure 9. Image of misorientation distribution of ultralow-temperature rolled alloy (a) before annealing and (b-d) after annealing for different times: (b) $3 \mathrm{~min}$, (c) $6 \mathrm{~min}$, and (d) $10 \mathrm{~min}$.

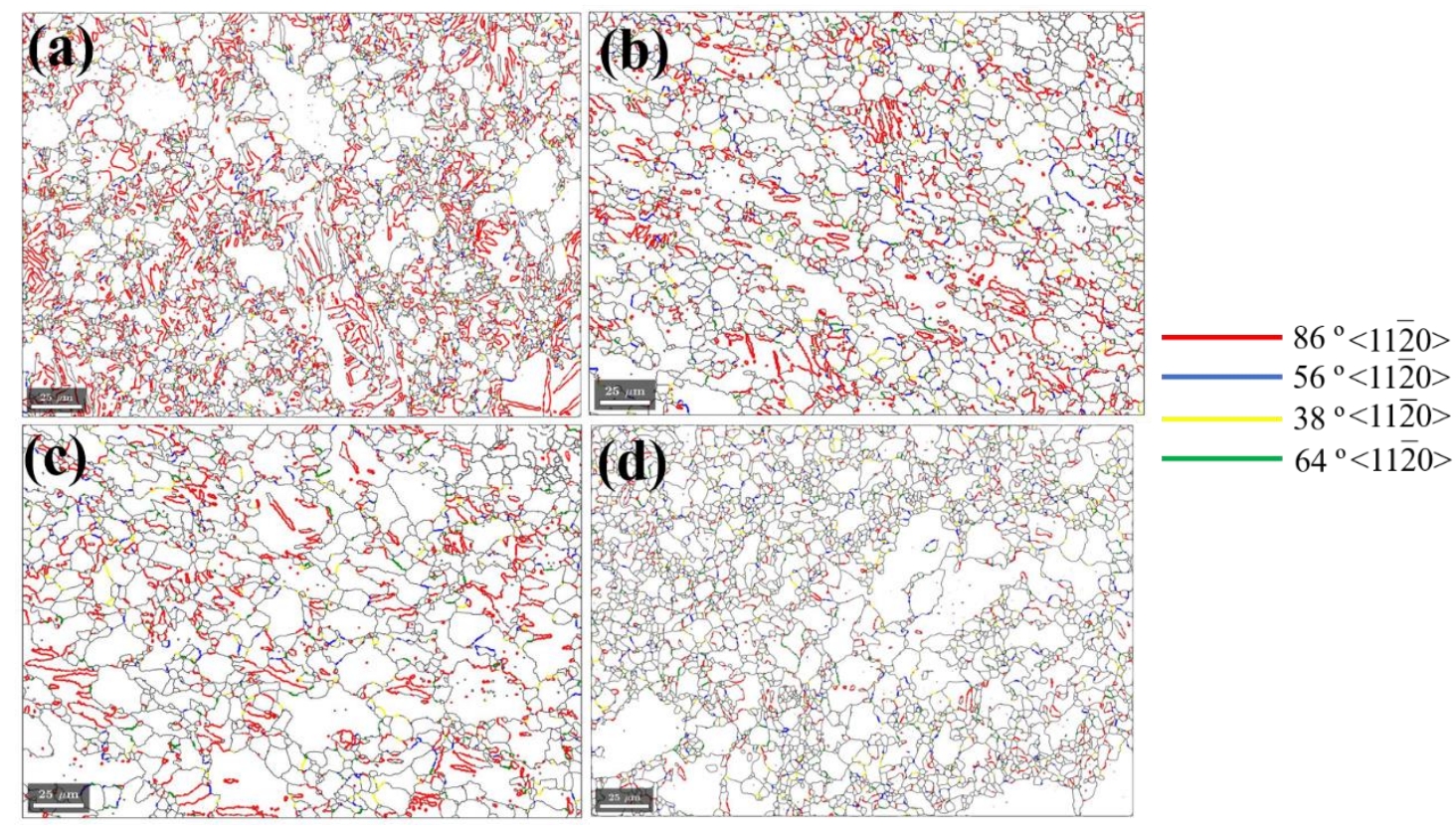

Figure 10. Twin boundary distribution of ultralow-temperature rolled alloy (a) before annealing and (b-d) after annealing for different times: (b) $3 \mathrm{~min}$, (c) $6 \mathrm{~min}$, and (d) $10 \mathrm{~min}$. 


\subsection{Mechanical Properties}

Figure 11 shows a graph of the trend in microhardness change for the alloy before and after annealing at $350{ }^{\circ} \mathrm{C}$ for different times. As the annealing time increased, the average hardness of the alloy gradually decreased by $10.32 \%$ from the original value of 63.12 to $56.6 \mathrm{HV}$. When the alloy was deformed at ultralow temperature, it was difficult for dislocations to slip and climb, which promoted work hardening. Work hardening produced relatively large stresses and strain accumulation in the ultralow-temperature rolled alloy, resulting in many twins and a relatively high dislocation density. Dislocations moved and entangled into cells, resulting in a relatively high hardness. Annealing the sample for different times released the internal stress in the material and reduced the dislocation density and twin content, thereby weakening the work hardening and texture; static recrystallization and nucleation of crystal grains in regions of high-distortion energy produced new undistorted grains such that the hardness gradually decreased. After the annealing time exceeded $10 \mathrm{~min}$, the recrystallized grains began to grow. The grain size had little effect on the hardness, which was therefore maintained within a certain range. The interaction between dislocations and between dislocations and twins, the texture, and the accumulated strain were all factors that significantly changed the microhardness of the ultralow-temperature rolled magnesium alloy after annealing.

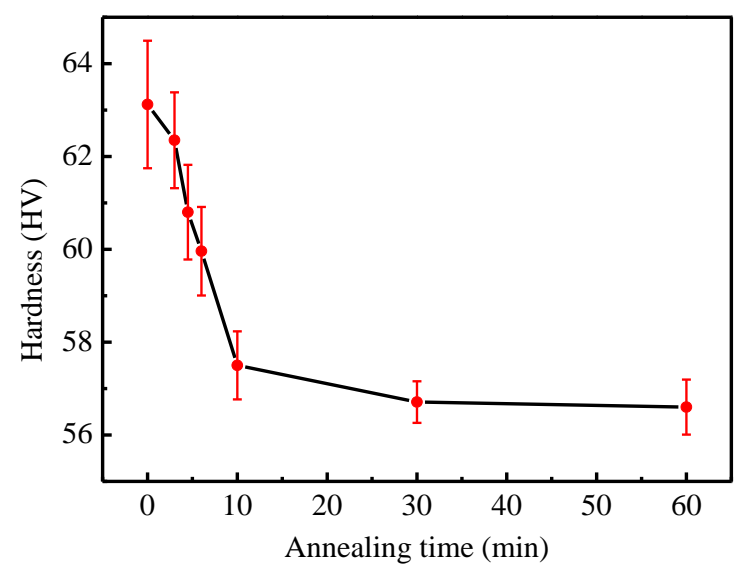

Figure 11. Microhardness of ultralow-temperature rolled alloy before and after annealing for different times.

In the annealing process, the recrystallization grains are refined by increasing the recrystallization nucleation rate and hindering the growth of grains. The alloy is deformed by ultralow-temperature rolling, and a large number of defects, such as dislocations and twins, are formed, that is, deformation storage energy, which provides a greater driving force for static recrystallization during the annealing process, thereby increasing the recrystallization nucleation rate. At the same time, the formation of a large number of twins can increase the grain boundary energy inside the grains so that there is not enough driving force for the growth of the grains, which effectively hinders the growth of the grains and obtains fine recrystallized grains. Figure 12 and Table 1 shows the corresponding data statistics for the alloy before and after annealing at $350{ }^{\circ} \mathrm{C}$ for different times. It can be seen from Figure 12 that the ultralow-temperature rolled alloy had high ultimate tensile strength (UTS) and low elongation (EL). On the one hand, in conjunction with the alloy shown in Figure 4a, it can be seen that after four passes of ECAP and ultralow-temperature rolling, ultrafine crystal twins were formed to produce fine grain strengthening and grain boundary strengthening. The twin boundaries could be equivalent to the effect of grain boundaries, effectively hindering the movement of dislocations and preventing plastic deformation of the material; when the dislocations moved to the twin grain boundary or the continuous accumulation of the grain boundary, the linear defect density inside the material increased, thereby promoting improvement of the material strength. Therefore, the ultralow-temperature rolling formed a large number of twin grain boundaries and pro- 
duced grain boundary strengthening. On the other hand, combined with Figure $6 a, c$, it can be seen that due to multiple deformations of the alloy, a large number of dislocations were formed to form dislocation entanglement to produce dislocation strengthening. In general, fine grain strengthening, dislocation strengthening, and grain boundary strengthening all make contributions to high tensile strength. With the extension of the annealing time, the tensile strength of the alloy decreased and the elongation increased. After annealing of ultralow-temperature rolled alloy, its tensile strength reduced because of reduction in the dislocation density and twin boundary content. The alloy recrystallized during the annealing process, the material became soft, and its elongation increased. Combining the recrystallized grain distribution in Figure 5, it can be seen that when the recrystallization fraction was low $(11.62 \%)$, the corresponding elongation was very low $(11 \%)$. The elongation of the alloy was significantly improved when the recrystallization fraction reached $39.55 \%$, increasing from $11 \%$ to $29 \%$. After the alloy was annealed at $350{ }^{\circ} \mathrm{C}$ for $10 \mathrm{~min}$, the tensile strength decreased from the original 245.89 to $186.15 \mathrm{MPa}$.

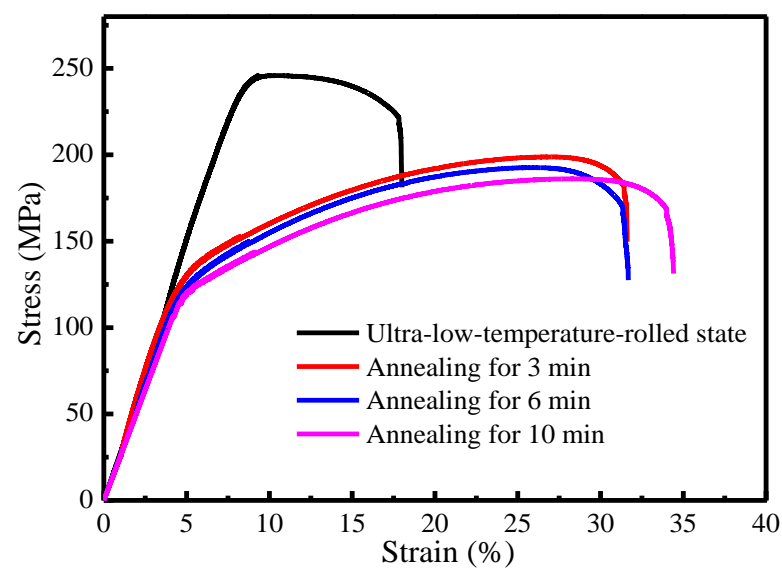

Figure 12. Stress-strain curves of ultralow-temperature rolled alloy before and after annealing for different times.

Table 1. Mechanical properties of ultralow-temperature rolled alloy before and after annealing for different times.

\begin{tabular}{ccc}
\hline Sample & Ultimate Tensile Strength (UTS/MPa) & Elongation (EL/\%) \\
\hline Ultralow-temperature rolled state & 245.89 & 11 \\
Annealing for 3 min & 198.8 & 26 \\
Annealing for 6 min & 192.64 & 25 \\
Annealing for 10 min & 186.15 & 29 \\
\hline
\end{tabular}

\section{Conclusions}

1. The alloy was treated with ECAP to obtain fine grains. Ultralow-temperature rolling introduced a large number of high-energy defects, such as grain boundaries and dislocations, which served as preferential nucleation sites during subsequent annealing for recrystallized grain formation. The twins formed by tension exerted along the $c$-axis during rolling under ultralow temperatures were mainly $\{10 \overline{1} 2\}<\overline{1} 011>$ tensile twins.

2. Increasing the annealing time at $350{ }^{\circ} \mathrm{C}$ resulted in the gradual completion of the static recrystallization process. The walls of the cells formed by dislocation entanglement flattened and formed subcrystalline grains during annealing, thereby gradually decreasing the twin content and the proportion of small-angle grain boundaries.

3. By increasing the annealing time at $350^{\circ} \mathrm{C}$, the hardness decreased by $10.32 \%$ from 63.12 to $56.6 \mathrm{HV}$, the tensile strength of the alloy was reduced from 245.89 to $186.15 \mathrm{MP}$, and the plasticity of the alloy significantly increased by $34.48 \%$ from $11 \%$ to $29 \%$. 
Author Contributions: H.Y. conceived and designed the experiment, collected the data, analyzed the data, and wrote the paper; Y.T. (Yun Tan) contributed to retrieving documents; and W.L. and Y.T. (Yuanbiao Tan) checked and revised the paper. All authors have read and agreed to the published version of the manuscript.

Funding: This work was supported by the National Natural Science Foundation of China (51661007), the Science and Technology Plan Project of Guizhou Province ([2019] 5303), and the Cultivation Project of Guizhou University ([2019] 15).

Data Availability Statement: No new data were created or analyzed in this study. Data sharing is not applicable to this article.

Conflicts of Interest: The authors declare that they have no known competing financial interests or personal relationships that could have appeared to influence the work reported in this paper.

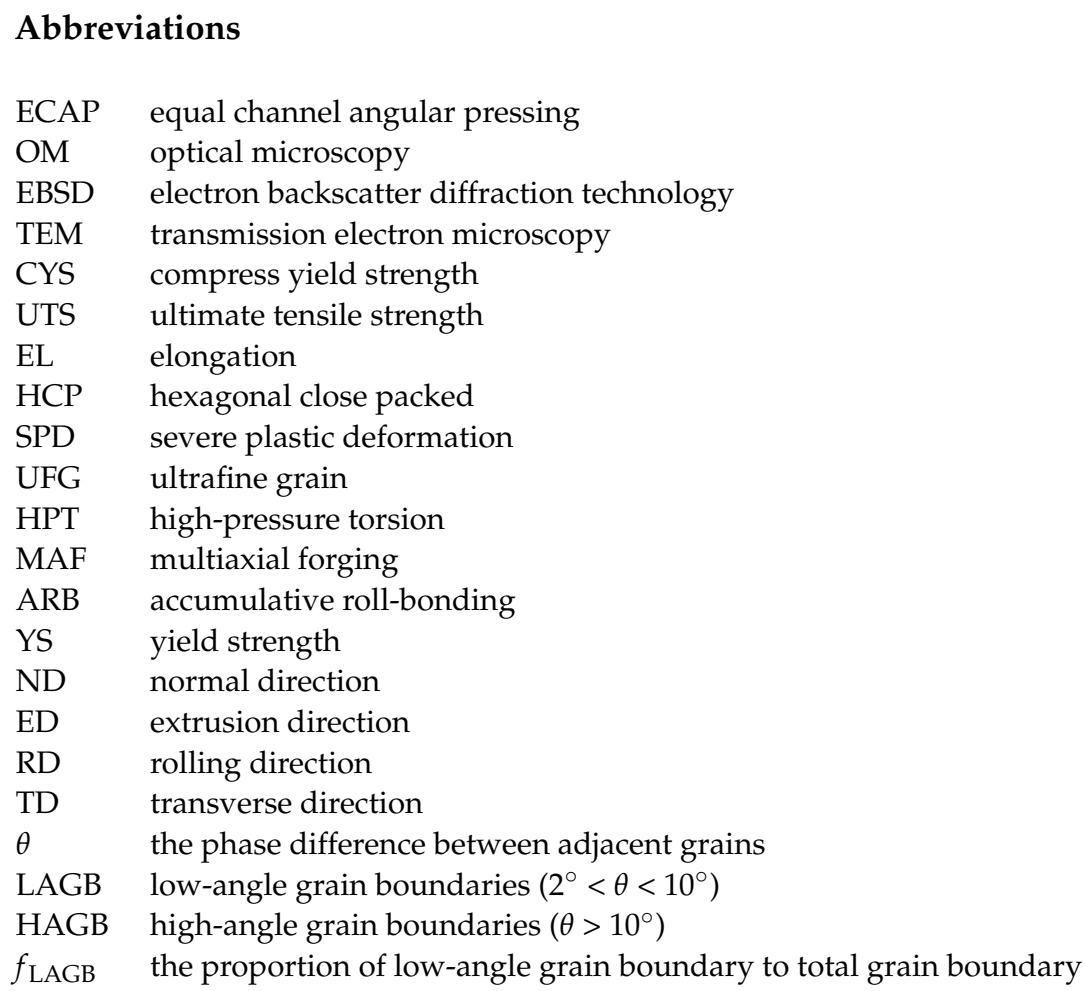

\section{References}

1. Adel, A.; Danil, P.; Ivan, E.; Mohamed, T.; Mahmoud, S.; Magdy, E.R. ANN Surface Roughness Optimization of AZ61 Magnesium Alloy Finish Turning: Minimum Machining Times at Prime Machining Costs. Materials 2018, 11, 808.

2. Jing, T.W.; Yin, D.L.; Jin, Q.L.; Tao, J.; Yan, L.S.; Xiang, Z. Effect of grain size on mechanical property of Mg-3Al-1Zn alloy. Scr. Mater. 2008, 59, 63-66.

3. Liu, Q.; Zhou, X.; Zhou, H.; Fan, X.; Liu, K. The effect of extrusion conditions on the properties and textures of AZ31B alloy. J. Magn. Alloy 2017, 5, 202-209. [CrossRef]

4. Reed-Hill, R.E.; Robertson, W.D. Additional modes of deformation twinning in magnesium. Acta Metall. $1957,5,717-727$. [CrossRef]

5. Atik, K.; Efe, M. Twinning-induced shear banding and its control in rolling of magnesium. Mater. Sci. Eng. A 2018, 725, 267-273. [CrossRef]

6. Edalati, K.; Yamamoto, A.; Horita, Z.; Ishihara, T. High-pressure torsion of pure magnesium: Evolution of mechanical properties, microstructures and hydrogen storage capacity with equivalent strain. Scr. Mater. 2011, 64, 880-883. [CrossRef]

7. Schafler, E.; Pippan, R. Effect of thermal treatment on microstructure in high pressure torsion (HPT) deformed nickel. Mater. Sci. Eng. A 2004, 387, 799-804. [CrossRef]

8. Bhowmik, A.; Biswas, S.; Dhinwal, S.S.; Sarkar, A.; Ray, R.K.; Bhattacharjee, D.; Suwas, S. Microstructure and Texture Evolution in Interstitial-Free (IF) Steel Processed by Multi-Axial Forging. Mater. Sci. Forum 2012, 702-703, 774-777. [CrossRef]

9. Shamsolhodaei, A.; Zarei-Hanzaki, A.; Moghaddam, M. Structural and functional properties of a semi equiatomic NiTi shape memory alloy processed by multi-axial forging. Mater. Sci. Eng. A 2017, 700, 1-9. [CrossRef] 
10. Duan, J.Q.; Quadir, M.Z.; Xu, W.; Kong, C.; Ferry, M. Texture balancing in a fcc/bcc multilayered composite produced by accumulative roll bonding. Acta Mater. 2017, 123, 11-23. [CrossRef]

11. Saito, Y.; Utsunomiya, H.; Tsuji, N.; Sakai, T. Novel ultra-high straining process for bulk materials-Development of the accumulative roll-bonding (ARB) process. Acta Mater. 1999, 47, 579-583. [CrossRef]

12. Matsubara, K.; Miyahara, Y.; Horita, Z.; Langdon, T.G. Developing superplasticity in a magnesium alloy through a combination of extrusion and ECAP. Acta Mater. 2003, 51, 3073-3084. [CrossRef]

13. Tham, Y.W.; Fu, M.W.; Hng, H.H.; Pei, Q.X.; Lim, K.B. Microstructure and Properties of Al-6061 Alloy by Equal Channel Angular Extrusion for 16 Passes. Adv. Manuf. Processes 2007, 22, 819-824. [CrossRef]

14. Beyerlein, L.J.; Tóthb, L.S. Texture evolution in equal-channel angular extrusion. Prog. Mater. Sci. 2009, 54, 427-510. [CrossRef]

15. Jahadi, R.; Sedighi, M.; Jahed, H. ECAP effect on the micro-structure and mechanical properties of AM30 magnesium alloy. Mater. Sci. Eng. A 2014, 593, 178-184. [CrossRef]

16. Garces, G.; Muñoz-Morris, M.A.; Morris, D.G.; Adeva, P.; Perez, P. Optimization of strength by microstructural refinement of MgY_2Zn_1 alloy during extrusion and ECAP processing. Mater. Sci. Eng. A 2014, 614, 96-105. [CrossRef]

17. Sarker, D.; Friedman, J.; Chen, D.L. De-twinning and Texture Change in an Extruded AM30 Magnesium Alloy during Compression along Normal Direction. J. Mater. Sci. Technol. 2015, 31, 264-268. [CrossRef]

18. Sarker, D.; Friedman, J.; Chen, D.L. Twin Growth and Texture Evolution in an Extruded AM30 Magnesium Alloy During Compression. J. Mater. Sci. Technol. 2014, 30, 884-887. [CrossRef]

19. Sarker, D.; Chen, D.L. Detwinning and strain hardening of an extruded magnesium alloy during compression. Scr. Mater. 2012, 67, 165-168. [CrossRef]

20. Sarker, D.; Chen, D.L. Dependence of compressive deformation on pre-strain and loading direction in an extruded magnesium alloy: Texture, twinning and de-twinning. Mater. Sci. Eng. A 2014, 596, 134-144. [CrossRef]

21. Sarker, D.; Friedman, J.; Chen, D.L. Influence of pre-strain on de-twinning activity in an extruded AM30 magnesium alloy. Mater. Sci. Eng. A 2014, 605, 73-79. [CrossRef]

22. Sarker, D.; Chen, D.L. Texture transformation in an extruded magnesium alloy under pressure. Mater. Sci. Eng. A 2013, 582, 63-67. [CrossRef]

23. Lei, L.; Shen, Y.; Chen, X.; Qian, L.; Lu, K. Ultrahigh Strength and High Electrical Conductivity in Copper. Science 2004, 304, 422-426.

24. Zhang, D.D.; Yang, Q.; Guan, K.; Li, B.S.; Wang, N.; Qin, P.F.; Jiang, B.; Sun, C.; Qin, X.; Tian, Z.; et al. A high-strength low-rare-earth-alloyed magnesium alloy via traditional hot-extrusion. J. Alloy Compd. 2019, 810, 151967. [CrossRef]

25. Cepeda-Jiménez, C.M.; Molina-Aldareguia, J.M.; Pérez-Prado, M.T. Origin of the twinning to slip transition with grain size refinement, with decreasing strain rate and with increasing temperature in magnesium. Acta Mater. 2015, 88, 232-244. [CrossRef]

26. Drouven, C.; Basu, I.; Al-Samman, T.; Korte-Kerzel, S. Twinning effects in deformed and annealed magnesium-neodymium alloys. Mater. Sci. Eng. A 2015, 647, 91-104. [CrossRef]

27. Sarker, D.; Friedman, J.; Chen, D.L. Influence of pre-deformation and subsequent annealing on strain hardening and anisotropy of AM30 magnesium alloy. J. Alloy Compd. 2014, 611, 341-350. [CrossRef]

28. Kim, Y.J.; Lee, J.U.; Kim, S.H.; Kim, Y.M.; Park, S.H. Grain size effect on twinning and annealing behaviors of rolled magnesium alloy with bimodal structure. Mater. Sci. Eng. A 2019, 754, 38-45. [CrossRef]

29. Song, D.; Li, C.; Liang, N.N.; Yang, F.L.; Jiang, J.H.; Sun, J.P.; Wu, G.S.; Ma, A.B.; Ma, X.L. Simultaneously improving corrosion resistance and mechanical properties of a magnesium alloy via equal-channel angular pressing and post water annealing. Mater. Des. 2019, 166, 107621. [CrossRef]

30. Chen, W.Z.; Ma, L.M.; Chen, X.M.; Cui, G.R.; Zhang, W.C.; Wang, E.D. Microstructure evolution and mechanical performance improvement of thin ZK61 magnesium alloy sheets subjected to cumulative cold rolling and intermediate annealing. Mater. Sci. Eng. A 2018, 733, 350-360. [CrossRef]

31. Guo, F.; Pei, R.S.; Jiang, L.Y.; Zhang, D.F.; Korte-Kerzel, S.; Al-Samman, T. The role of recrystallization and grain growth in optimizing the sheet texture of magnesium alloys with calcium addition during annealing. J. Magn. Alloy 2020, 8, 252-268. [CrossRef]

32. Matsuda, M.; Ii, S.; Kawamura, Y.; Ikuhara, Y.; Nishida, M. Interaction between long period stacking order phase and deformation twin in rapidly solidified Mg97Zn1Y2 alloy. Mater. Sci. Eng. A 2004, 386, 447-452. [CrossRef]

33. Christian, J.W.; Mahajan, S. Deformation twinning. Prog. Mater Sci. 1995, 39, 1-157. [CrossRef] 